\title{
Reação Cultural à Aquisição: Estudo do Caso Santander/Noroeste
}

\author{
Agnaldo de Jesus Rossini \\ João Marcelo Crubellate \\ Ariston Azevêdo Mendes
}

\section{Resumo}

No presente estudo nos propomos analisar aspectos culturais como fatores de aceitação ou resistência ao processo de aquisição do Banco Noroeste pelo Banco Santander. Os dados foram coletados junto a dois grupos de funcionários (administrativo, com funções rotineiras e operacional, com cargos de direção) de uma agência específica daquela organização. Em termos dos aspectos culturais, a ênfase recaiu sobre crenças e valores compartilhados naqueles grupos, identificados por meio de entrevistas semi-estruturadas, seguidas de análise de conteúdo. Os resultados permitiram identificar os valores e crenças no grupo operacional como favoráveis ao processo de aquisição. Já no grupo administrativo, alguns aspectos foram identificados como fatores de aceitação e outros como fatores de resistência ao processo. Os resultados apontam para a diferenciação cultural em relação à aquisição. São exploradas algumas possíveis razões para a não ocorrência de forte reação contrária ao processo, mesmo em face da forte prescrição de novos artefatos culturais pelo banco adquirente.

Palavras-chaves: aquisição; cultura organizacional; mudança.

\begin{abstract}
The main purpose of this study was to analyse the cultural reaction to an acquisition process. The case study was based upon values and beliefs shared out among employees of a Brazilian Bank recently acquired by the Spanish group Santander Bank - as patterns of acceptance or resistance to that process. To access the necessary data, we interviewed a sample of employees at Santander Bank's agency in the city of Maringá, Brazil. Our revision of the managerial literature had pointed out that, if an integration process is not properly conducted or don't exist (that means that the acquisition process was probably conducted in an impositive way) the resistance will probably be stronger. In spite of that, our study allowed us to identify a cultural acceptance to the acquisition process in the administrative group of employees (managers), and only a partial resistance in the operational group (clerks), in that specific case. Those results showed a differentiated cultural pattern in relation to the fast organizational change in that agency. Finally, we try to present some possible reasons to those results by discussing aspects related to the role of member's interests in the acceptance/resistance to organizational change processes and the power of big economic organizations towards civil society.
\end{abstract}

Key words: acquisition; organizational culture; organizational change. 


\section{INTRODUÇÃO}

Nas últimas décadas vêm ocorrendo grandes transformações no ambiente de organizações financeiras em todo o mundo, caracterizando-se tal ambiente pelo aumento da velocidade das mudanças, tanto quanto pelo aumento da agressividade competitiva. Entre os aspectos relevantes nesse contexto observa-se a concretização de várias aquisições e fusões entre bancos como estratégia de enfrentamento a essa acirrada concorrência e ao processo de globalização.

Também dentro desse amplo contexto de transformações mundiais, as organizações bancárias no Brasil iniciam esforços no sentido de buscar soluções para os seus problemas gerenciais, resultando muitas vezes na implementação de aquisições ou fusões com outras organizações nacionais e estrangeiras, como alternativa para a sobrevivência. Para os bancos nacionais parece que se torna cada vez mais difícil sustentar a luta contra as organizações estrangeiras pelo domínio do mercado nacional: os recursos externos, a maior experiência daquelas organizações e o seu maior grau de profissionalização, resultante de envolvimento mais intenso e há mais tempo, com graus elevados de concorrência, afetam definitivamente essa competição no país.

Além disso, como conseqüência dessa turbulência, torna-se maior a busca por alternativas gerenciais e técnicas que possibilitem incremento no grau de competitividade das organizações em face dos seus concorrentes: explica-se assim certa ênfase em novos conceitos e idéias como possíveis ferramentas para tal alavancagem, e a noção de cultura organizacional, ainda que evidentemente não sujeitando-se a tamanha expectativa de instrumentalização, vem recebendo atenção por parte de acadêmicos e profissionais do setor.

Algumas das principais preocupações em relação à cultura têm relação com a possibilidade de interferência dos aspectos culturais, gerados socialmente pelo grupo ou prescritos por indivíduos e grupos específicos, dependendo de diferentes perspectivas teóricas, nas mudanças organizacionais necessárias para a sobrevivência em face do novo contexto. Como a cultura se compõe de padrões profundamente enraizados, deles pode depender, por exemplo, parcela do sucesso ou insucesso nos processos de aquisição ou fusão, além da orientação na elaboração de outras ações estratégicas que se façam necessárias.

Em qualquer perspectiva analítica que se adote, portanto, a consideração dos aspectos culturais aparece como relevante para o entendimento de possíveis desencadeamentos em face da implantação de novos sistemas gerenciais, tecnoló- 
gicos ou políticos nas organizações. Se a formação de padrões culturais se dá no processo de convivência social, apenas para mencionar um pressuposto relevante no contexto deste estudo, qualquer mudança organizacional que afete aqueles padrões poderá ser limitada pela dimensão de tempo, porque, quanto mais radical e rápida for tal mudança, menor tempo haverá para adaptações ou para o surgimento de novos padrões em resposta àquelas mudanças, resultando possivelmente em maior resistência das pessoas na organização.

Neste artigo analisamos essas considerações em uma circunstância específica: a aquisição do Banco Noroeste pelo Grupo Santander no período de 1998 e 1999. A amostra restringiu-se a uma única agência do banco, na cidade de Maringá (PR). A pergunta de pesquisa que encaminhou o presente estudo foi: a cultura organizacional (valores e crenças) dos grupos operacional e administrativo da Agência Maringá do Banco Santander atuam como fator de aceitação ou de resistência ao processo de aquisição do banco?

\section{Fusóes e Aquisições como Processos de Transformação Organizacional}

Desde o fim da Segunda Guerra Mundial, estamos assistindo a enormes transformações na economia mundial. As mudanças de cunho mais específico e operacional, que se dão em termos das organizações econômicas, sociais e governamentais, apresentam-se sob diversas formas e são resultantes das pressões ora vividas no âmbito interno e externo daquelas organizações, representando o impulso para a manutenção ou reconfiguração de posições competitivas no mercado.

Esta reestruturação nas organizações adquire relevância, nas últimas décadas, sob a forma de vários mecanismos destinados a aumentar a competitividade ou, no mesmo sentido, afetar a concorrência em determinado setor ou mercado. Destacam-se, entre outros mecanismos, os processos de joint-venture, fusão e aquisição. No presente artigo interessa-nos mais diretamente a análise do processo de aquisição em um caso específico, enfocando a dimensão cultural da organização como possível fator interveniente nos resultados daquele processo e, dessa forma, como fator explicativo (entre outros aspectos correntemente apresentados, por exemplo, por Nadler e Limpert [1993]) do insucesso de vários casos de aquisição.

Em termos da distinção entre aquisições e fusões, Lopes (1996, p. 382) afirma: "nas aquisições, a empresa incorporada pode ser transformada em uma divisão ou departamento da adquirente. Por outro lado, na fusão os envolvidos na opera- 
ção deixam de existir e surge uma empresa totalmente nova". Pode-se aceitar, portanto, que no processo de aquisição, por conta de sua natureza, ocorrerá prescrição ou imposição de padrões, técnicos e não-técnicos (culturais, por exemplo) de uma organização sobre a outra. Já em termos das fusões, deve-se esperar o surgimento de novos padrões por meio de acordos entre as partes envolvidas.

No tocante às aquisições, é reconhecido que elas vêm sendo mecanismo muito utilizado no ambiente econômico e organizacional norte-americano, a partir da década de 80. A principal explicação para tal ênfase parece ser a possibilidade de se conseguir trazer para as empresas escalas de sinergia pela combinação de pontos fortes, competências e posições no mercado, além da questão específica da escala de produção, em alguns casos (Nadler e Limpert, 1993). Outro aspecto é que as aquisições podem proporcionar crescimento e renovação de forças da organização em face das mudanças de ordem global, por permitir maior estabilidade e, conseqüentemente, poder em termos do ambiente organizacional.

Esses fatores podem justificar o recorde alcançado em meados de 1997, quando o valor envolvido em aquisições, fusões e joint-ventures, em termos mundiais, ultrapassou em US\$130 milhões o valor correspondente a 1996, com predominância das empresas norte-americanas (Kuchenbecker, 1998). Outro fator que parece ter contribuído para este recorde é o baixo custo do dinheiro para financiar as aquisições, o que encoraja bancos, companhias telefônicas e grandes laboratórios a adquirirem outras companhias em todo o mundo, ou com elas se fundirem.

Na Europa, por outro lado, a questão da globalização demorou para ser aceita pela ampla maioria das organizações. Deve-se, contudo, lembrar que há um diferencial significativo em termos do ambiente político europeu em relação ao norteamericano: o pluralismo ideológico que, historicamente, caracteriza o ambiente europeu parece dificultar o processo de aceitação da união de organizações de diferentes países, o que não ocorre na América do Norte. Assim, constitui-se na Europa um contexto institucional diferente daquele existente nos Estados Unidos, onde se tende a interpretar fusões e aquisições como modo de estimular a produtividade das empresas, enquanto na Europa, por vezes, continua difícil aceitar como parceiro um rival (Villinger apud Kuchenbecker, 1998).

Em termos de análise teórica da questão das aquisições e do seu impacto organizacional, as duas principais abordagens analíticas são a perspectiva estratégica e a de recursos humanos. A primeira tem foco nos aspectos financeiros e estratégicos, isto é, em dimensões mais objetivas do processo; a segunda analisa o impacto que a aquisição pode desencadear sobre as pessoas envolvidas, isto é, a preocupação com a sua reação às mudanças e como elas enfrentam o processo de conviver, ainda que temporariamente, com altos índices de incerteza e insegurança, ou o que se tem convencionado chamar de síndrome da fusão (Marks e 
Mirvis apud Kuchenbecker, 1998). Essa segunda perspectiva principalmente implica reconhecer que a questão cultural tem grande influência no processo de aquisição de uma empresa.

Para Nadler e Limpert (1993) as duas perspectivas acima não podem oferecer, isoladamente, as respostas necessárias para que se conduza a bom termo uma aquisição. Para eles, a maioria das propostas de aquisições ou fusões têm centrado atenção em uma ou outra das perspectivas: alguns que trabalham na perspectiva estratégica atentam pouco para os problemas de interação; outros, que focalizam as questões de recursos humanos, muitas vezes o fazem num vazio estratégico. Reconhecem, portanto, a existência de uma lacuna na teoria de aquisição, apontando a necessidade de se adotar uma perspectiva que contemple tanto a gestão dos recursos humanos quanto as questões estratégicas. A essa terceira perspectiva, chamam de dinâmica organizacional.

A perspectiva da dinâmica organizacional, segundo Nadler e Limpert (1993), centraliza as suas atenções no planejamento e análise do que ocorre depois da aquisição: dá foco ao processo de integração que se segue à aquisição. Assim, nessa perspectiva, a aquisição pode ser entendida também como processo de mudança organizacional, recebendo ênfase a análise da passagem de um estado atual, no momento da aquisição, para um estado futuro, depois de encerrado o processo de integração.

Quando se utiliza a idéia de administração da mudança em relação à aquisição, pode-se perceber a importância da adequada compreensão do período de integração entre organização adquirida e organização adquirente. Antes da aquisição, há duas empresas diferentes, com métodos de trabalho, estratégias, objetivos e aspectos culturais potencialmente diferentes. Depois, há a necessidade de se constituir uma única organização, geralmente pela absorção da adquirida pela adquirente.

Em termos da dimensão humana e, conseqüentemente, dos aspectos culturais implicados no processo, é exatamente nessa etapa de transição que poderão ocorrer as maiores dificuldades, podendo comprometer toda a aquisição, mesmo que esta se tenha pautado por adequados padrões operacionais. Os encaminhamentos nessa etapa geralmente têm grande influência no processo geral, chegando até a determinar a eficiência do processo de mudança.

Nesse sentido, Porter (1987) aponta que uma significativa parte das aquisições tem obtido resultados decepcionantes. Possivelmente isso ocorra devido à má análise do mercado, à falta de conhecimento em relação à organização adquirida, à estratégias sem adequada definição e à superavaliação dos ativos, ou seja, houve uma compra errada; mas também é possível pensar-se que há casos em 
que a compra foi correta, mas a administração da integração ou pós-aquisição não foi adequadamente concertada. Como afirmam Nadler e Limpert (1993), problemas originados da incompatibilidade cultural e estresse entre funcionários são causas importantes de parte dos problemas em várias aquisições. Os mesmos autores indicam que os casos bem sucedidos compõem-se de três fases com as seguintes ênfases: na pré-aquisição, a estratégia; durante a negociação, o planejamento da integração; e na pós-aquisição, a administração da integração.

Conforme forem os objetivos envolvidos na aquisição, isto é, proteção ou expansão da participação no mercado, os encaminhamentos em cada fase do processo tenderão a apresentar especificidades. Alguns aspectos, entretanto, são necessários, a despeito da natureza das intenções: o conhecimento das características principais da organização compradora e da organização a ser adquirida; o conhecimento do grau de diferenciação entre ambas, em todos os aspectos em que seja possível essa análise, mas principalmente em termos estruturais, estratégicos e culturais; e o conhecimento do contexto da transação.

Conforme sugerem Nadler e Limpert (1993), a teoria da aquisição refere-se exatamente a esse esforço para conhecimento dos vários aspectos importantes relacionados à decisão e ao processo de aquisição, vinculando-se o objetivo principal de qualquer aquisição à expectativa de que a união entre as organizações implicadas no processo venha alavancar o seu potencial, gerando valor que beneficie uma delas (a adquirente) ou ambas.

Investigações relacionadas às aquisições, contudo, apontam que a maioria delas são realizadas tendo como preocupação principal o período de pré-aquisição, especialmente com os aspectos financeiros da organização adquirida (Nadler e Limpert, 1993; Barbosa, 1996). Em certo sentido, a maioria das adquirentes demonstram grande preocupação com o que a adquirida poderá proporcionar em termos de alavancagem financeira e estratégica, centrando-se "na análise da complementaridade estratégica entre as empresas adquirentes e adquiridas à luz dos aspectos relacionados com o setor, o mercado e a tecnologia" (Barbosa, 1996). Já na fase de pós-aquisição, principalmente o aspecto da integração é o que vem recebendo menor atenção por parte de pesquisadores e de agentes envolvidos nos processos de implementação das aquisições.

Para Barbosa (1996, p. 361) a análise do período pós-aquisição, bem como a implementação das ações que se façam necessárias, devem dar-se numa perspectiva que ela qualifica como "organizativa", isto é, que evidencie "a compatibilidade das estruturas, das práticas socioculturais e de recursos humanos das duas empresas [isto porque] esta compatibilidade [ou incompatibilidade] afeta diretamente a integração dessas organizações uma vez consumada a aquisição". 
A abordagem organizativa, assim, parece oferecer adequada perspectiva para a continuação do processo de aquisição no período pós-aquisição. O conceito parece proporcionar direcionamento para ajuste entre as duas organizações naqueles aspectos em que apresentam incompatibilidades estruturais e culturais. Estes são, afinal, os principais aspectos que no processo de aquisição vêm sendo considerados secundários e por vezes têm sido esquecidos, justificando, em parte, o insucesso de muitas aquisições. No presente artigo assumimos que a dimensão cultural é um dos fatores mais importantes para a análise e implementação dos processos de aquisição.

\section{Cultura Organizacional e Reações à Mudança Organizacional}

A abordagem aos aspectos culturais não é tema recente na teoria organizacional, mas recebe ênfase nas últimas três décadas, devido à expectativa de se entender a influência de aspectos subjetivos da vida em sociedade sobre os processos organizacionais e administrativos. Por vezes essa expectativa adquire caráter prescritivo, de modo a tornar funcionais tais aspectos subjetivos para os objetivos e metas de grupos dominantes, como se percebe nos estudos de Schein (1992), Kotter e Heskett (1994), entre outros. Desconsideram o caráter acidental ou incidental de muitas das relações informais que se estabelecem no âmago da organização (Barnard, 1974) e que vão dar origem aos aspectos culturais que se tornam, se assim ocorrem, incontroláveis, em grande medida, por qualquer agente individual ou mesmo por algum grupo formal.

A cultura organizacional é entendida, na perspectiva do presente estudo, como fenômeno que se refere à criação e recriação da realidade por parte das pessoas na organização, na medida em que estabelecem contatos pessoais e desencadeiam trocas simbólicas, buscando interpretar o contexto com que lidam (Morgan, 1996). Essa interação simbólica dentro do grupo resulta na própria mudança do ser humano enquanto se relaciona, dando causa a um processo adequadamente descrito por Pettigrew (apud Freitas, 1991, p. 88): “O homem cria a cultura e a cultura cria o homem".

Nesse contexto de trocas simbólicas e de apreensão cognitiva da realidade, a cultura vai estar refletida, conforme sugerem Morgan (1996) e Feuerschütte (1997), entre outros, principalmente nos valores e nas crenças compartilhadas em termos do grupo, desencadeando a elaboração de juízos que terminam por orientar a fixação de objetivos e a escolha dos meios considerados necessários para o seu alcance. Valores e crenças são aqui entendidos, seguindo-se a idéia de 
Myrdal (1965), como referentes à intencionalidade ou percepção da realidade, distinguindo-se na medida que essa realidade é tomada como certa ou prescrita a partir de juízo do indivíduo. Assim, "as pessoas têm idéias a respeito de como a realidade de fato é ou foi [crenças] e também as têm a respeito de como a mesma deveria ser ou ter sido [valores]" (Myrdal, 1965, p. 124).

Certamente a possibilidade de intervenção nos aspectos culturais de qualquer agrupamento social, tanto a possibilidade objetiva quanto os aspectos da legitimidade desses esforços, passam por considerações relacionadas ao poder que interventores, sejam indivíduos ou grupos, possuam na relação social com o agrupamento que sofre a intervenção. Interessante nesse sentido é a opinião de Griffin (1996) de que a mudança organizacional, principalmente em caso de aquisição (de um novo "império", diz ele), deve-se dar da forma mais radical possível no primeiro momento, seguida de abrandamento posterior. Tenta justificarse o autor na prescrição maquiavélica. Entretanto, deve-se ter certo cuidado em tal análise, visto que nos deparamos aí com diferentes contextos: o de Maquiavel, onde há plena possibilidade do exercício da força como instrumento de imposição, e o contexto da organização moderna, onde essa possibilidade não é factível na mesma extensão. A idéia, contudo, parece fundamentar muitas das ações vinculadas aos processos de aquisição.

A noção de poder (e os aspectos correlatos, principalmente os interesses) está vinculada essencialmente à noção de cultura organizacional. A idéia básica é que a cultura se forma em processo que demanda certo tempo de convivência e trocas sociais entre os agentes da realidade. Com base no pressuposto de que a cultura é dinâmica, mas não volátil (Martin, 1992), emerge debate teórico entre a possibilidade de a cultura organizacional atuar como fator de aceitação ou como fator de resistência às mudanças organizacionais. Alinhados à primeira possibilidade estão principalmente os defensores de modelos de gestão vinculados aos processos de mudança radical e inovação nas organizações. Nessa perspectiva, é quase uma necessidade lógica e, sem dúvida ideológica, pensar na cultura como possuindo status objetivo e passível de manipulação consciente por parte de indivíduos ou grupos na organização. A impossibilidade desse controle, pelo menos de forma plena, e o pressuposto de que a cultura é socialmente gerada em processo com certa dependência temporal para o estabelecimento das relações sociais, embasam a percepção de cultura como fator de resistência às mudanças prescritas exteriormente ao grupo, principalmente quando tais mudanças se derem em curto período de tempo.

Apesar das atitudes extremas, a questão acima parece mais bem encaminhada, quando se adota compreensão intermediária, aceitando-se ambas as possibilidades, isto é, que os aspectos culturais podem atuar como fatores de aceitação 
ou de resistência, de forma não sistemática ou sem qualquer padrão inerente à dimensão cultural em si.

No seu estudo sobre a mudança estrutural em uma organização do ramo de informática, Feuerschütte (1997) identifica valores naquela organização como fator de aceitação à mudança. Já Crubellate e Machado-da-Silva (1998), estudando valores e crenças em departamentos de uma universidade pública, apontam a cultura como fator de aceitação à mudança, em alguns casos, e como fator de resistência em outros.

Ambos os estudos isentam-se de qualquer postura extrema. Em ambos os estudos, igualmente, os aspectos culturais são estudados em vínculo com a questão das relações de poder. No segundo estudo, o caráter público da organização abordada, aliado à sua estrutura colegiada, evidentemente com menor possibilidade relativa de intervenção ou imposição de novos padrões por agentes externos ou por parte da cúpula da organização, pode explicar o que se identificou quanto aos aspectos culturais em relação à mudança.

No presente estudo, defendemos o pressuposto de que a aquisição, como processo vinculado a uma mudança radical na organização adquirida, esbarra no aspecto tempo enquanto fator essencial para a formação/mudança cultural. Espera-se que a prescrição de novos parâmetros para as atitudes e ações dos membros organizacionais, comum a esses processos, e evidenciada no presente caso, como pode ser observado no tópico O Caso em Estudo, encontre nos aspectos culturais certa resistência às mudanças requeridas.

\section{Aspectos Metodológicos}

Este trabalho caracteriza-se como estudo de caso, que objetiva o exame de determinado fenômeno, teoricamente delimitado, em contexto real específico, utilizando-se várias fontes de evidência. O objetivo principal foi avaliar a relação entre aspectos culturais específicos, conforme se apresentam em uma agência do Banco Santander, e o processo de aquisição ocorrido recentemente por conta da compra do Banco Noroeste pelo Banco Santander. A agência que serviu como caso (Banco Santander, Agência Maringá, PR) é composta por 23 funcionários, sendo 11 da área operacional, responsáveis pela comercialização dos serviços do banco, isto é, Gerente Geral, Gerentes de Negócio e Assistentes de Gerente; e 12 da área administrativa, ligados às atividades administrativas e rotineiras. 
No esforço da pesquisa, buscou-se: (1) identificar os valores e as crenças dos funcionários da área operacional e da área administrativa; (2) avaliar se esses valores e crenças, na área operacional e administrativa, atuam como fator de aceitação ou de resistência ao processo de aquisição do Banco Noroeste pelo Banco Santander; (3) avaliar possíveis conseqüências da aceitação ou da resistência cultural ao processo de aquisição, em face das estratégias adotadas para implementar a aquisição. Os dados utilizados no estudo foram coletados de fontes secundárias, como publicações e periódicos de circulação aberta e publicações internas da organização abordada e principalmente de fontes primárias, em que se utilizou o recurso de entrevistas semi-estruturadas realizadas pessoalmente pelos autores deste artigo. Foram realizadas, ao todo, 11 entrevistas, entre os dias 25 de abril e 17 de maio de 1999. O processo de amostragem se deu em duas etapas: na primeira, intencionalmente, amostragem por conveniência, dividiu-se a população de 23 funcionários, com base na sua atuação no banco, isto é, funcionários da área operacional ou da área administrativa; na segunda etapa, realizouse seleção aleatória de 11 funcionários, sendo 6 da área administrativa e 5 da área operacional do banco, que foram então contatados e entrevistados para a coleta de dados. As entrevistas foram gravadas, transcritas e em seguida submetidas a análise de conteúdo.

\section{O Caso em Estudo: A aquisição do Banco Noroeste pelo Banco SANTANDER}

O Grupo Santander é de origem espanhola e tem presença em vários países, contando com 8.691 agências, 106.500 funcionários e 22 milhões de clientes, de acordo com dados do início de 1999.

O processo de aquisição, que é objeto do presente estudo, teve início no primeiro trimestre de 1998. O primeiro sinal de que realmente havia interesse na aquisição do Banco Noroeste pelo Grupo Santander, segundo fontes internas, foi a presença de auditores com "sotaque castelhano" nos corredores da matriz do Banco Noroeste. Logo não haveria mais como esconder que o processo já entrava em vias de tornar-se realidade. Essa, entretanto, não seria a primeira movimentação do grupo espanhol para a entrada no mercado financeiro do Brasil. Na verdade, o Banco Santander entrou no mercado brasileiro com a compra do Banco Geral do Comércio, compondo-se então o grupo Banco Santander do Brasil. Autorizado pelo Banco Central, o Banco Santander do Brasil passou a analisar outras possibilidades de aquisições, com a finalidade de rápida expansão no mercado brasileiro e ganho em carteira de clientes. Enfim, a compra do Ban- 
co Noroeste se concretizou em meados de julho de 1998, após várias negociações, com um valor divulgado em torno de $\mathrm{R} \$ 480$ milhões.

Em termos da Agência Maringá, a notícia da compra foi inicialmente recebida como boa novidade pelos funcionários do Banco Noroeste. Todas as informações obtidas a respeito da atuação internacional do Banco Santander eram favoráveis: no ano anterior o grupo havia alcançado ótimos resultados no seu balanço final. A divulgação da compra foi inicialmente realizada de forma discreta pela imprensa, o que foi positivo para o banco, porque evitou maiores preocupações entre acionistas e clientes.

No mês seguinte, agosto de 1998, todos os gerentes das agências do Banco Noroeste foram convocados para uma reunião em São Paulo com o Presidente do Banco Santander. Na recepção desta primeira reunião, foram distribuídas camisetas com a logomarca Santander, sendo solicitado aos gerentes que as vestissem para participar da reunião, ressaltando-se que a partir daquela data "todos eram funcionários do Banco Santander". Em apenas um final de semana todas as agências no país passaram a utilizar a bandeira do Banco Santander nas suas dependências físicas. Todos os formulários, painéis, fachadas, placas, canetas, broches, chaveiros e réguas foram mudados. Em comunicado interno, solicitouse a todos os funcionários que rasgassem o talão de cheques do Banco Noroeste e passassem a usar somente o do Banco Santander.

Após essa ênfase na imediata reformulação dos artefatos, certo clima de receio começou a predominar entre os funcionários da agência. No mesmo período, o setor de recursos humanos do grupo enviou mala direta a cada funcionário, afirmando que não ocorreriam demissões e que o quadro seria aproveitado no novo grupo, principalmente nas novas agências a serem abertas pelo Banco Santander. Logo em seguida, implementou-se uma série de projetos na tentativa de demonstrar a valorização do funcionário no novo banco. Inicialmente, ocorreu uma avaliação de desempenho pessoal; depois, implantaram-se projetos como o Promove (promoção interna de funcionários) e o Banco de Sugestões, além de novos seguros de vida e outras medidas.

Em outubro de 1998, começou o processo de integração de sistemas informacionais entre as duas partes do grupo no Brasil, o Santander Noroeste e o Santander Brasil, antigo Banco Geral do Comércio. Concomitantemente, começou a ocorrer pressão por parte da matriz para o aumento da produtividade dos funcionários e o alcance dos objetivos prescritos para as agências. No fluxo dessas transformações gerenciais e operacionais, em janeiro de 1999, instala-se o programa de reengenharia de processos, com alterações significativas nos padrões operacionais até então costumeiros no banco adquirido. 
O processo de transição perdurou todo o ano de 1999, sendo as exigências do adquirente justificadas pelo Grupo Santander como necessárias para a adequação das antigas agências Noroeste aos padrões internacionais do Banco Santander. Este estudo, portanto, retrata aspectos ainda em desencadeamento em uma das agências envolvidas naquele processo, com possíveis conseqüências e contornos futuros que, obviamente, não foram plenamente antecipados no escopo deste trabalho.

\section{ANÁlise dos DAdOS}

Os dados obtidos no presente estudo permitiram identificar um conjunto de valores e crenças relacionado ao processo de aquisição ocorrido recentemente na organização estudada. Alguns desses aspectos culturais foram identificados em ambos os grupos de funcionários da Agência Maringá(PR). A maioria deles, contudo, se apresentou como específico a apenas um dos dois grupos, sugerindo que, no presente caso, estamos lidando com grupos culturais distintos ou diferenciados.

A análise daqueles dados obtidos com os funcionários selecionados para o estudo, permite observar que os aspectos culturais na área operacional (OP) se apresentam favoráveis ao processo de aquisição do banco (vide Quadro 1).

\section{Quadro 1: Valores/Crenças - Grupo Operacional}

\begin{tabular}{|l|}
\hline PROFISSIONALISMO \\
\hline MUDANÇA \\
\hline COMPROMETIMENTO COM A ORGANIZAÇÃO \\
\hline RECONHECIMENTO PROFISSIONAL \\
\hline PRESSÃO SOBRE OS FUNCIONÁRIOS FAZ PARTE DO PROCESSO DE AQUISIÇÃO \\
\hline MUDANÇA É A TÔNICA DO MERCADO FINANCEIRO \\
\hline DEMISSÃO É UM PROCESSO NATURAL NA AQUISIÇÃO \\
\hline
\end{tabular}

Fonte: entrevistas realizadas com funcionários do Banco Santander.

O primeiro valor a se destacar em relação ao grupo operacional é o profissionalismo. Para os funcionários desse grupo, o relacionamento entre indivíduo e organização, no período anterior à aquisição, era notadamente paternalista. Muitas questões de relevância para o banco eram tratadas em termos pessoais, resolvidas freqüentemente por intermédio da influência pessoal e da amizade entre as partes envolvidas. 
Dentro da nova perspectiva administrativa que se instala no período pós-aquisição, as questões gerenciais e operacionais, na perspectiva daqueles funcionários, assumem caráter mais profissional e mais condizente com as atuais necessidades da organização, em face do novo panorama ambiental enfrentado. Assim é que, para um dos entrevistados, "[Os dois bancos] nada têm a ver um com o outro; o processo [no novo banco] é totalmente empresarial e, de fato, até então o banco era uma coisa paternalista. Hoje nós somos uma empresa de fato" (OP1).

Outro aspecto cultural merecedor de destaque é a noção de que as pessoas, principalmente na sua atividade profissional dentro das organizações, devem estar propensas a se adaptarem a novos padrões, a novos processos e exigências. Como foi sugerido por um dos entrevistados do grupo operacional: "Um exemplo, se esse assistente não tiver faculdade, qual é a intenção dele? Fazer [curso superior]. Se ele não for fazer, ele está fora do processo. Hoje você tem que ter a capacidade de aceitar a mudança. Se não aceitar, você está fora" (OP3).

Dessa flexibilidade dos indivíduos em aceitar, ou mesmo, como parece ser a sugestão, buscar ativamente alterações no seu trabalho, dependeria a própria organização para a sua eficiência, porque se admite mesmo que essa seja uma imposição do próprio mercado, em que atuam as organizações financeiras; de forma mais ampla, é tendência da própria sociedade contemporânea. A aquisição, é necessário ressaltar, apresenta-se, na percepção daqueles funcionários, como parte desse amplo contexto de pressão ambiental sobre as organizações e como processo em nada estranho aos indivíduos preparados para a nova realidade profissional. Em face dessas percepções, pode-se apontar a mudança como um valor aceito no grupo operacional:

"Nós temos que adotar estas novas metodologias de trabalho. Não é só o Santander, é o HSBC e outros bancos [que estão mudando]" (OP2).

"Independente do banco ter sido comprado por um banco estrangeiro ou não, iria ocorrer as mudanças" (OP5).

Relacionada a esse valor, a crença de que mudança é a tônica do mercado financeiro aparece também como fator relevante para o entendimento dos aspectos culturais aqui analisados e da sua relação com o processo de aquisição, que é objeto desse estudo. Como foi sugerido, com a globalização, os crescentes esforços de aquisições e fusões no contexto organizacional tornaram-se fatores relevantes e praticamente inescapáveis, exigindo esforço das organizações menores para se adequarem ao novo contexto. A sugestão que se apresenta no escopo dessa análise é que a aquisição veio em momento oportuno, permitindo acompanhar as mudanças do mercado financeiro, num claro apontamento de que o Banco Noroeste não conseguiria acompanhar toda essa evolução. 
Destacou-se ainda a noção compartilhada entre os membros daquele grupo de que a ascensão profissional na nova organização está e deve estar relacionada ao comprometimento dos funcionários no alcance dos objetivos propostos pelo banco. O vestir a camisa é jargão que aparece, naquele contexto cultural, como expressão do comprometimento enquanto vínculo esperado do indivíduo com a empresa: "[A intenção] é crescer, crescer, crescer. Vestir a camisa mesmo. Não ficar parado dentro do banco" (OP1).

Alguns entrevistados apresentaram também certa percepção crítica quanto aos critérios utilizados pela nova organização para avaliar o potencial profissional dos funcionários, principalmente centrados no grau de escolaridade. Para esses entrevistados a organização deveria reconhecer outros aspectos, como experiência de trabalho e tempo de dedicação à empresa como requisitos para a ascensão na carreira interna: "Eu acho que o que o Banco está querendo é inovar o quadro de funcionários, pessoas novas para ele moldar e não uma pessoa com experiência, para evitar um funcionário com vícios" (OP4).

Esse aspecto sugere que o reconhecimento profissional é um valor naquele grupo, apresentando-se como o único dos aspectos identificados que tem relação aparentemente negativa com o processo de aquisição, na medida em que alguns funcionários não se sentem contemplados nesta política de promoção. $O$ resultado, contudo, não vem sendo posturas de resistência, mas de esforço daqueles profissionais para completar a sua educação formal, algumas vezes retornando às escolas para a realização ou conclusão de cursos superiores e cursos de pósgraduação.

Uma possível explicação para essa ação daqueles funcionários encontra-se na crença de que as pressões sobre os funcionários constituem-se em processos inerentes à aquisição. Como expressou um dos entrevistados: "Exigese de você $101 \%$ [de esforço] e você não pode ser só aquilo que exigem de você, você deve fazer mais e mais" (OP1).

Ao assumir essa explicação como válida, os funcionários assumem, concomitantemente, a responsabilidade pelo problema com que se defrontam: se tais pressões e exigências são naturais ao processo de aquisição, é o indivíduo quem deve a elas se adaptar, e não esperar que o processo seja alterado para contemplar o indivíduo.

O último aspecto cultural identificado nesse grupo é a expectativa de que, ao se profissionalizar, a organização deixa de ter necessidade da presença de grande número de funcionários, sendo assumida como natural a sua demissão. Pode-se perceber isso na avaliação que faz um dos entrevistados: "Em todas as corporações em que isso ocorrer, vai haver demissões mesmo. Quando um banco adqui- 
re outra organização, e há mais funcionários do que é necessário, o que ele vai fazer? Demite mesmo" (OP2).

A demissão de funcionários como conseqüência natural nos processos de aquisição aparece, portanto, como crença arraigada naquele grupo, concluindo a composição do quadro cultural vigente no grupo operacional do Banco Santander, em relação à recente aquisição.

Já com relação aos aspectos culturais identificados entre funcionários do grupo administrativo (AD), a aceitação do processo não é tão evidente quanto no primeiro grupo (vide Quadro 2). Principalmente as crenças identificadas no grupo administrativo se apresentam como aspectos de aceitação ao processo, mas os valores parecem significar uma consciente resistência quanto à aquisição, o que sugere uma situação mais complexa, na organização estudada, do que a esperada de início, demandando esforço explicativo que a seguir buscamos encaminhar.

\section{Quadro 2: Valores/Crenças - Grupo Administrativo}

\begin{tabular}{|l|}
\hline PROFISSIONALISMO \\
\hline SEGURANÇA \\
\hline INTEGRAÇÃO ENTRE OS FUNCIONÁRIOS \\
\hline FLEXIBILIDADE \\
\hline EQÜIDADE NO TRATAMENTO \\
\hline DEMISSÃO É UM PROCESSO NATURAL DA AQUISIÇÃO \\
\hline DEMISSÃO FAZ PARTE DA EVOLUÇÃO TECNOLÓGICA \\
\hline AUTO-ATENDIMENTO É A SOLUÇÃO DOS PROBLEMAS OPERACIONAIS \\
\hline
\end{tabular}

Fonte: entrevistas realizadas com funcionários do Banco Santander.

Como no grupo operacional, também entre os funcionários do grupo administrativo o profissionalismo evidencia-se como valor compartilhado, significando nesse grupo a percepção daqueles indivíduos de que a nova administração do banco extinguiu muitos procedimentos paternalistas em relação aos funcionários, instaurando processos mais impessoais de avaliação, de ascensão interna e de comunicação.

Apontavam-se também os aspectos favoráveis da informatização de muitos procedimentos internos e até os diferentes padrões de relacionamento entre o banco e os seus clientes, vigentes após a aquisição, como desejáveis para a adequação da organização às exigências do mercado e mesmo para a solução de alguns problemas não tão amplos, a despeito dos possíveis impactos negativos dessas questões para os funcionários (demissões, por exemplo). Alguns dos entrevistados ressaltam: "pouco paternalismo e mais profissionalismo. Sair de uma cultura paternalista para outra puramente profissional" (AD4). 
Relacionado a esse aspecto, podem-se apontar como crenças neste grupo as noções de que demissão é um processo natural na aquisição e que demissões fazem parte da evolução tecnológica. É interessante ressaltar a relação favorável que esses aspectos culturais parecem ter no concernente ao processo de aquisição e como principalmente essas crenças manifestas expressam certo grau de apatia daqueles funcionários, em face de situações que lhes são notadamente desfavoráveis. Algumas manifestações, a seguir transcritas, tornam mais evidente essa contradição:

"Então eu só estou esperando [a demissão]. É uma realidade que nós temos que enfrentar" (AD2).

"Não vejo perspectivas, só mais demissão na entrada de mais máquinas" (AD 5).

Ainda nesse sentido pode-se apontar como crença a idéia de que o auto-atendimento, resultado da instalação de máquinas multifuncionais nas agências, em substituição a funcionários, é a solução dos problemas operacionais. Esses funcionários demonstram aceitar como fato que as novas tecnologias e novos processos de trabalho no setor bancário significarão a obsolescência das suas capacidades profissionais, sendo a demissão a conseqüência natural ou óbvia. Percebe-se aqui também evidente postura cordial dos funcionários perante a realidade com que se defrontam e em face da organização, ao aceitarem que nada podem fazer, e nem a organização pode, para reverter essa situação. $O$ contexto desses aspectos culturais favoráveis ao processo de aquisição sugere que os funcionários do grupo administrativo entendem como sendo um problema exclusivamente seu a adequação aos novos parâmetros exigidos pelo banco, assumindo também a quase total responsabilidade (é praticamente uma aquiescência) pelo possível afastamento do quadro de funcionários.

Isto não se dá, contudo, sem que apareçam críticas às mudanças que estão sendo implementadas. Alguns funcionários queixaram-se da falta de informações no período imediatamente anterior à aquisição, relativas mesmo ao que se estava planejando, o que os teria deixado na dependência de boatos para entender a situação que se estava desencadeando. Logo após confirmar-se a aquisição, a situação, segundo alguns dos entrevistados, não se alterou, isto é, eles continuaram sem saber o que iria acontecer e quais seriam os novos métodos e políticas de trabalho do novo banco. Percebe-se assim que segurança é um valor relevante no contexto da análise que aqui buscamos encaminhar e que pela própria natureza da aquisição, com a mudança organizacional que lhe é conseqüente, apresenta-se como fator de resistência ao processo.

Também para alguns funcionários, um dos problemas que já existia antes da 
aquisição, e que se agravou após, é a falta de união entre os membros da organização.

“A distância entre a gerência e os funcionários já era grande e agora piorou mais ainda. A divisão que existia entre a área administrativa e a diretoria era uma barreira grande. Agora aumentou esta barreira" (AD2).

“A gente sente uma falta de união e companheirismo" (AD5).

Para esses funcionários, a área administrativa deveria receber mais informações relacionadas aos objetivos da organização e ao seu próprio trabalho, para que esse fosse realizado de modo mais integrado em relação às outras partes da organização. Esses aspectos, diferentes em certo sentido, porém relacionados, permitem apontar que integração entre os funcionários é um valor compartilhado naquele grupo.

Essa falta de informações para o desenvolvimento das atividades, segundo alguns funcionários, intensificou-se sob a nova administração.

"[Existe] muita burocracia. Ninguém sabe te responder nada. Um passa para o outro e ninguém resolve nada" (AD1).

"Existe muita hierarquia mesmo. A gente chega lá e conversa com alguém e é muito complicado. Eu achei que ficou bastante complicado" (AD2).

A percepção é de que, para o desenvolvimento das atividades, o trabalho deveria ser organizado com maior flexibilidade. O excesso de normas e padrões impostos estaria resultando em atraso dos serviços, afetando as relações entre o banco e os seus clientes. Para alguns, isso significa falta de confiança do banco nos seus funcionários.

Por fim, pode-se identificar certo desconforto por parte dos membros do grupo administrativo no que concerne às oportunidades de ascensão na organização e mesmo à própria realização do trabalho. Apontou-se que funcionários do grupo operacional recebem mais instruções, cursos e preparação para a sua atuação em face das mudanças, recebendo, conseqüentemente, mais oportunidades para progredir nas suas respectivas carreiras, quando essas oportunidades deveriam ser oferecidas igualmente a todos. A eqüidade no tratamento recebido na organização é, portanto, um último valor que se pode identificar no grupo administrativo. Pode-se perceber que, dos aspectos culturais identificados nesse grupo específico, ao contrário do grupo operacional, alguns mostraram-se como fatores de aceitação do processo de aquisição, enquanto certos valores apresentaram-se claramente como fatores de resistência ao processo, caracterizando-se uma situação de ambigüidade cultural. 


\section{Consideraçóes Finais}

No presente estudo buscou-se analisar o impacto da cultura organizacional no processo de integração pós-aquisição, no caso específico da aquisição do Banco Noroeste pelo Banco Santander. O pressuposto inicial era de que a ênfase apenas em aspectos técnicos do processo não seria suficiente para explicar os seus possíveis desencadeamentos, nem serviria como parâmetro exclusivo para as ações administrativas necessárias. Considerou-se, a princípio, mais adequada a perspectiva organizativa (Barbosa, 1996), que prescreve a análise do processo em dimensões outras além da técnica, principalmente a dimensão cultural.

Os resultados alcançados sugeriram, contudo, que mesmo a perspectiva organizativa ainda não parece suficiente para abranger e explicar todas as possibilidades de desencadeamentos em face das mudanças organizacionais decorrentes da aquisição. Constatou-se aqui que os aspectos culturais identificados foram amplamente favoráveis às mudanças implementadas, em um dos grupos, e apresentaram-se de forma controversa e ambígua, em outro. A despeito da forte intervenção nos aspectos culturais implementada pela nova administração, a cultura naqueles grupos, mesmo no segundo, não se mostrou como fator de evidente resistência à aquisição. Sugere-se, portanto, que há necessidade de agregação de outras variáveis intervenientes, para que se possa compreender, com maior segurança, o complexo fenômeno da mudança organizacional provocada por intervenções radicais planejadas, como é o processo de aquisição.

Neste caso específico, deve-se estar atento para o fato de que o grupo administrativo, e não o grupo operacional, é que apresenta certos aspectos de resistência. Uma possível razão para isso talvez possa ser encontrada nas políticas de recursos humanos adotadas pela administração do banco adquirente, amplamente favoráveis a alguns interesses dos membros do grupo operacional, enquanto não se apresentam da mesma forma em relação aos interesses do grupo administrativo. Como sugere Feuerschütte (1997), os processos de reação às mudanças podem ser mais bem compreendidos, quando analisados também na perspectiva das relações de poder que se desencadeiam no interior da organização, principalmente na busca pela legitimação de interesses individuais ou dos grupos envolvidos. Assim, o processo parece ocorrer em termos de certa troca entre organização e indivíduos do grupo operacional: estes aceitam a forte intervenção nos seus padrões culturais em troca da expectativa do atendimento, por parte da organização, de alguns dos seus interesses.

Entretanto tal explicação não oferece resposta para as posturas identificadas no grupo administrativo: por qual razão não ocorre frontal resistência ao processo 
de aquisição que, sem dúvida, atingiu certos interesses daquele grupo? Talvez a idéia de legitimidade das ações organizacionais contribua para esse entendimento. Em contexto como o brasileiro, caracterizado por distanciamento do poder, aversão ao conflito e importação de tecnologias, entre outras características relacionadas à dimensão ambiental, é possível que a aceitação de ações que se fundamentam em argumentos técnicos e na autoridade do especialista, seja obtida com maior facilidade. É importante destacar que as crenças compartilhadas naquele grupo parecem coincidir com crenças difundidas no contexto social brasileiro mais amplo, principalmente o acentuado caráter de cordialidade do brasileiro, fundamentado que parece ser no pressuposto de que a realidade social possui status tão objetivo quanto a realidade física ou natural. Em sociedades mais bem articuladas e prontas à mobilização para defesa de interesses próprios, intervenções como a apresentada neste caso possivelmente sofreriam forte resistência.

Da perspectiva dos indivíduos envolvidos no processo, a garantia da manutenção do emprego de alguns é a contrapartida à aceitação de maior grau de padronização técnica e, principalmente, cultural, como aliás parece ser a tônica no contexto social do mundo globalizado. As suas conseqüências certamente merecem tratamento mais detalhado do que nos permite o escopo desta conclusão. Limitamo-nos a sugerir que a exploração acadêmica desta questão é necessária para o entendimento de possíveis desdobramentos sociais, econômicos e humanos da atual sociedade de organizações, cada vez mais sociedade de mercado.

\section{ReferênCias Bibliográficas}

\section{BARBOSA, J. D.}

Análise dos aspectos organizativos nas fusões e aquisições de empresas. In: XX ENCONTRO ANUAL DA ANPAD (1996 : Angra dos Reis). Anais... Rio de Janeiro : ANPAD, 1996. p. 357372.

BARNARD, C.

As funções do executivo. São Paulo : Atlas, 1974.
CRUBELLATE, J. M.; MACHADO-DA-SILVA, C. L.

Mudança ambiental e adaptação organizacional : estudo comparativo de casos departamentais na UEM. Organizações e Sociedade, v. 5, n. 13. p. 37-61, set./ dez. 1998. 
FEUERSCHÜTTE, S. G.

Cultura organizacional e dependências de poder : a mudança estrutural em uma organização do ramo de informática. Revista de Administração Contemporânea, v. 1, n. 2, p. 73-95, mai./ago. 1997.

FREITAS, M. E. DE.

Cultura organizacional : formação, tipologias e impacto. São Paulo : Makron/ McGraw-Hill, 1991.

GRIFFIN, G. R.

Maquiavel na administração : como jogar e ganhar o jogo do poder na empresa. São Paulo : Atlas, 1996.

KOTTER, J.;

HESKETT, J.

A cultura corporativa e o desempenho empresarial. São Paulo : Makron Books, 1994.

KUCHENBECKER, N. F.

Estratégia de crescimento e mudança estrutural : o caso da empresa Brasilsat Harald S.A. Curitiba, 1998. Dissertação (Mestrado em Administração) - Centro de Pesquisa e Pós-Graduação em Administração, Universidade Federal do Paraná.

LOPES, H. E. G.

Cultura e organizações : efeitos nas fusões, aquisições e formação de alianças estratégicas. In: XX ENCONTRO ANUAL DA ANPAD (1996: Angra dos Reis). Anais... Rio de Janeiro : ANPAD, 1996. p. 373-392.

MARTIN, J.

Cultures in organizations : three perspectives. Oxford : Oxford University Press, 1992.

MORGAN, G.

Imagens da organização. São Paulo: Atlas, 1996.

MYRDAL, G.

$O$ valor em teoria social. São Paulo : Pioneira, 1965.

NADLER, D. A.;

LIMPERT, T. M.

Administração da dinâmica das aquisições : como passar com sucesso da decisão à integração. In: NADLER, D. et al. Arquitetura organizacional. 2. ed. Rio de Janeiro : Campus, 1993. p. 51-68.

PORTER, M.

From competitive advantage to corporate strategy. Harvard Business Review, v. 3, p. 4359, 1987.

SCHEIN, E.

Organizational culture and leadership. 2. ed. London : Jossey-Bass, 1992. 